\title{
Observations of the Germination Behavior of Tilletia indica Teliospores on the Soil Surface under Varying Simulated Environmental Conditions
}

\author{
Gary L. Peterson ${ }^{*}$, Dana K. Berner ${ }^{1}$, John G. Phillips ${ }^{2}$ \\ ${ }^{1}$ USDA ARS Foreign Disease-Weed Science Research UnitFort, Detrick, USA \\ ${ }^{2}$ USDA-ARS-North Atlantic Area, Wyndmoor, USA \\ Email: ^gary.peterson@ars.usda.gov
}

How to cite this paper: Peterson, G.L., Berner, D.K. and Phillips, J.G. (2017) Observations of the Germination Behavior of Tilletia indica Teliospores on the Soil Surface under Varying Simulated Environmental Conditions. American Journal of Plant Sciences, 8, 2878-2897.

https://doi.org/10.4236/ajps.2017.811196

Received: August 30, 2017

Accepted: October 28, 2017

Published: October 31, 2017

Copyright $\odot 2017$ by authors and Scientific Research Publishing Inc. This work is licensed under the Creative Commons Attribution International License (CC BY 4.0).

http://creativecommons.org/licenses/by/4.0/

\begin{abstract}
A series of replicated growth chamber studies were conducted to determine the effects of soil type and simulated European temperature conditions from fall planting to anthesis in Hungary, United Kingdom, Italy and Norway on the initiation of Tilletia indica teliospore germination on the soil surface. A concurrent study examined effects on teliospore germination of a simulated temperature profile for Ciudad Obregon, Mexico, where Karnal bunt is known to occur. Three soil moisture treatments were tested; $40.5 \%$ water holding capacity (WHC), 16.2\% WHC and weekly fluctuation of soil WHC. Results suggest that soil type would not have a significant effect on germination during the cropping season. Under all conditions tested, some portion of the teliospore population remained dormant but viable throughout the entire season. In comparing Mexican and Hungarian temperature profiles, highest soil surface germination for the Hungarian profile was at $40.5 \%$ WHC during the first 30 days of the simulation ( 30 days after planting date). The highest germination for the Mexican profile was at the $16.2 \%$ WHC during the last 30 days of the study (time of anthesis).
\end{abstract}

\section{Keywords}

Karnal Bunt, Spore Survival, Field Population, Wheat Smut, Partial Bunt

\section{Introduction}

Tilletia indica Kuhn, the causal agent of Karnal bunt (KB) of wheat, is a pathogen of international regulatory concern. Although KB has little effect on wheat 
yield, it may result in reduced exports due to international phytosanitary trade barriers [1] [2]. Until 1996, the disease had been reported in India, Pakistan, Nepal, Iraq [3], Iran [4], Mexico [5], Brazil [6] and South Africa [7]. In 1996-97, KB was first reported from the South-western United States (U.S.) in Arizona, Southern California and Texas [8]. The disease has never been reported in Europe.

Many aspects about the physiological or epidemiological factors that determine $\mathrm{KB}$ spread and establishment potential are unknown. Unlike other wheat-infecting Tilletia species ( $T$. contraversa, T. tritici, and T. laevis), T. indica is not a systemic pathogen. Infection is initiated during flowering when the exposed glumes are penetrated by haploid allantoid secondary sporidia arising from germinating basidiospores that originated from teliospores germinating on the soil surface. The highest levels of disease are usually observed when cool temperatures, cloud cover and several days of rain occur during flowering [1] [9].

A number of studies were conducted in the U.S. and E.U. to determine the longevity of $T$. indica survival in soil [10] [11] [12] [13]. Studies were conducted using teliospores mixed in soil contained in micromesh bags. In some cases, the micromesh bags were enclosed in a second container to ensure teliospores could not escape into the environment after being buried in the field. These studies showed teliospore survival at different depths for greater than three years with noted differences in soil type and moisture conditions. One important question to be answered is whether physiological dormancy exists within a teliospore population on the soil surface that would assure that viable teliospores would be available to infect the host during anthesis or whether they would have all germinated outside the window of infection if early season temperature and moisture conditions were favorable.

Reported here are the results of several studies that focused on the behavior and viability of teliospores on the soil surface where teliospore germination and the source of infective secondary sporidia originate. Research was conducted under Federal and State permits within the USDA Agricultural Research Service Biosafety Level-3 Plant Disease Containment Facility at Fort Detrick, MD [14]. Replicated growth chamber studies were conducted to measure the effects of soil type on teliospore germination on the soil surface. A second replicated study looked at the effects of soil moisture (SM) on the viability of teliospores on the surface subjected to simulated minimum/maximum weekly average temperature profiles occurring between wheat planting time and the occurrence of anthesis in four different wheat growing regions in Europe and in a $T$. indica conducive area of Mexico. A portion of this study was previously reported in deliverables report to the European Commission Fifth Framework Project, "Risks Associated with Tilletia indica, the Newly-listed EU Quarantine Pathogen, The Cause of Karnal bunt of Wheat" [13] [15], hence the focus on temperatures occurring in European wheat production areas. That study has since been repeated and data 
sets merged here. Data are also presented in a replicated study of observed teliospore soil surface germination comparing the effects of SM and 5-year weekly average temperature profiles from planting date to anthesis for both Cd. Obregon, Mexico, where the disease is reported, and for Szolnuk, Hungary.

\section{Methods and Materials}

\subsection{Inoculum Production}

Inoculum (Tilletia indica teliospores) for all of the studies was produced each year by boot-injection in a $T$. indica contaminated field in Maricopa, AZ $\left(\mathrm{N} 32^{\circ} 59.1441, \mathrm{~W} 112^{\circ} 2.97966\right)$ under the appropriate State and Federal research permits. The permit required the use of one isolate obtained locally (Brawley, CA, USA 1998), however earlier research found no significant differences in germination and infection among geographically diverse isolates from Asia and the Americas [16]. The disease is not known to occur in Europe, specifically in the simulated regions.

Sori of infected kernels ruptured and passed though a $20 \mathrm{~cm}$ dia., no. 100 mesh sieve (Humboldt Mfg. Co., Elgin, IL) and teliospores collected in a tray below. Beginning in the fall of 1998 and in subsequent years, three $1.48 \mathrm{~m}^{2}$ plots were planted with WL-711 wheat. Forty Petri dishes containing $2 \%$ water agar augmented with ampicillin and streptomycin sulfate, $100 \mathrm{mg} / \mathrm{L}$ each, were seeded with teliospores two weeks before wheat boot development (Zadoks growth stage-49) following the method of Bonde et al. [16] to germinate teliospores and produce inoculum of infective secondary sporidia. When wheat reached boot stage with awns emerging, sporidia were washed off the dishes and the concentration adjusted to $1 \times 10^{3}$ sporidia/ml. During early evening, $1.0 \mathrm{ml}$ of inoculum was injected by syringe into every wheat boot in the three plots (Figure 1). Wheat heads were harvested in June, hand threshed and the bunted seed retained for experiments.

\subsection{Application of Teliospores to the Soil Surface}

In all 3 experiments, seeding of the soil surface with teliospores was accomplished using a spore-settling tower (Figure 2). Containers were placed in the bottom of the spore-settling tower along with five $10 \times 35 \mathrm{~mm}$ culture dishes containing $2 \%$ water agar. A modified $\mathrm{CO}_{2}$ pistol was fired which dispersed a

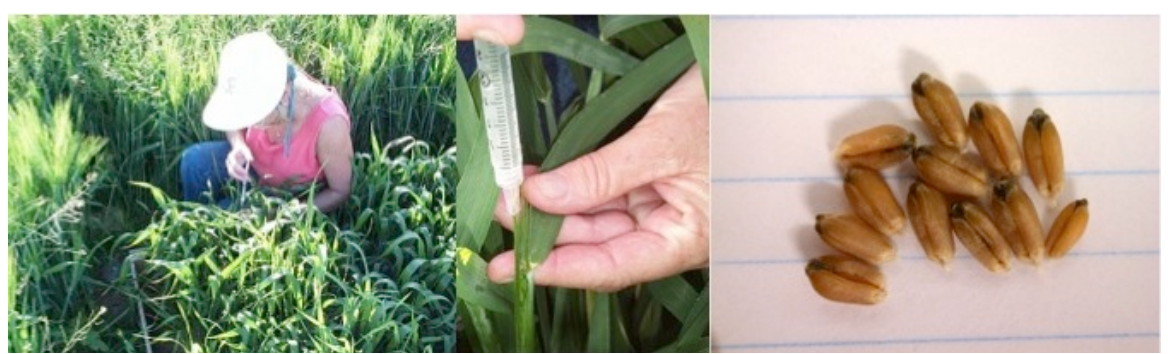

Figure 1. Inoculation of wheat plants for teliospore production and resulting infected kernels. 


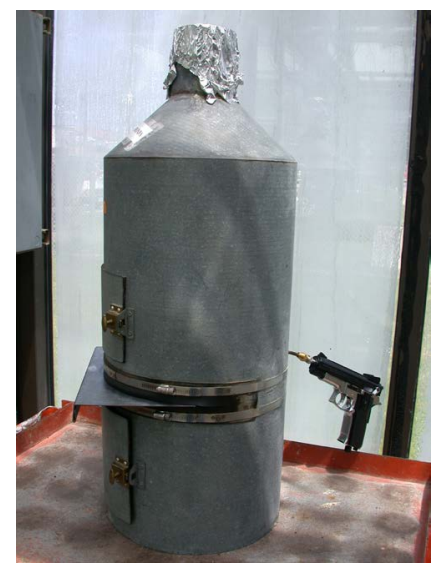

Figure 2. Spore settling tower used for soil surface inoculations.

cloud of teliospores into the upper chamber. After $3 \mathrm{sec}$ the partition between the upper and lower chambers was removed. The teliospores that were clumped together in the inoculum, being heavier than individual teliospores, fell at a faster rate and were trapped on the partition plate, allowing the lighter individual teliospores to fall onto the soil and water agar surfaces. Water agar plates were examined to determine the number of teliospores per $\mathrm{cm}^{2}$ and to confirm an even distribution of teliospores.

\subsection{Assessing Teliospore Germination on the Surface in Different Soils}

The soils utilized in the growth chamber studies were obtained from field plots in Maryland, Georgia, Montana, Arizona and Kansas. Soil analyses (Spectrum Analytic Inc., OH) are presented in Table 1. Soils were autoclaved for $40 \mathrm{~min}$ at $121^{\circ} \mathrm{C}$ then sifted through a 4.5/64 round metal screen, No. 0025 (Seedboro, Des Plaines, IL).

The water holding capacity (WHC) of each soil was determined by the method of Harding et al. [17]. Soils were maintained at $42 \%$ WHC throughout the experiment based on a previous report that this would support teliospore germination on soil [18]. For each soil type, $40 \mathrm{~g}$ of oven-dried soil were transferred to a $100-\mathrm{ml}$ round plastic sealable containers (Lock \& Lock, Anaheim, CA) three per soil type. The container and contents were weighed, and then $13-16 \mathrm{ml}$ of distilled water was slowly atomized over the surface of the soil (Figure 3). Containers were sealed overnight so the moisture would come to equilibrium throughout the soil. The lids were removed and water allowed to evaporate for 1 to 2 days until the weight was equivalent to $42 \%$ WHC for each soil type then lids were applied. For soil from AZ, MD, KS, MT, and GA, this was 10.4, 9.2, 5.0, 8.6 and $9.2 \mathrm{~g}$ of water, respectively.

\subsection{Application of Teliospores to the Soil Surface}

Seeding of the soil surface with teliospores was accomplished using a 


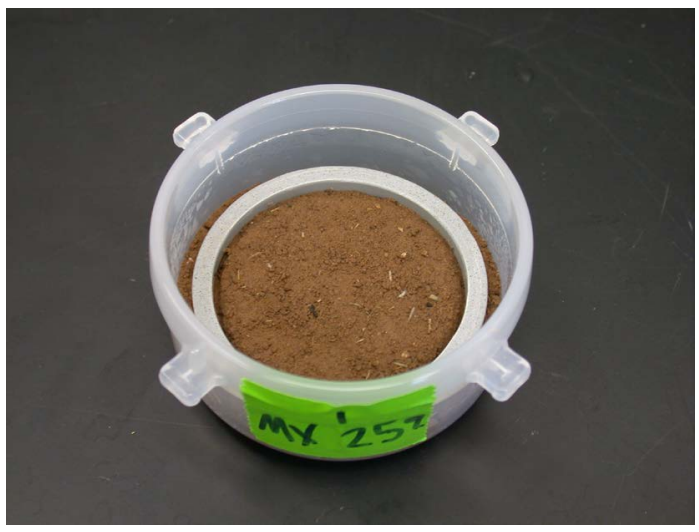

Figure 3. Soil in sealable plastic container for observing teliospore germination on the soil surface.

Table 1. Soils analysis.

\begin{tabular}{ccccccccccc}
\hline & \multicolumn{3}{c}{ Macronutrients [lbs/A] } & & $\underline{\text { Texture }}$ & Total & \multicolumn{2}{c}{ Soil } & \multicolumn{2}{c}{ \% Composition } \\
\hline$\underline{\text { Soils }}$ & $\underline{\mathbf{P}}$ & $\underline{\mathbf{K}}$ & $\underline{\mathbf{M g}}$ & $\underline{\mathrm{Ca}}$ & & $\underline{\text { OM }}$ & $\underline{\mathrm{pH}}$ & $\underline{\text { Sand }}$ & $\underline{\text { Silt }}$ & $\underline{\text { Clay }}$ \\
\hline MD & 24 & 388 & 182 & 1329 & loam & 1.7 & 6 & 49 & 30 & 21 \\
GA & 8 & 204 & 243 & 929 & sandy clay loam & 3.1 & 5.6 & 46 & 23 & 31 \\
MT & 100 & 1387 & 1039 & 4252 & silt loam & 2.1 & 6.6 & 29 & 56 & 15 \\
AZ & 117 & 1401 & 1597 & 10315 & clay loam & 2.0 & 7.4 & 28 & 40 & 32 \\
KS & 99 & 738 & 444 & 3455 & sandy loam & 0.7 & 6.9 & 57 & 38 & 5 \\
\hline
\end{tabular}

spore-settling tower previously described. For each soil type, one container was inoculated with three $20 \mathrm{mg}$ teliospore clouds for a total of $60 \mathrm{mg}$ for each treatment and replication.

Containers were placed in a growth chamber (Conviron E7/2, Pembina, ND) set at $18^{\circ} \mathrm{C}\left( \pm 2^{\circ} \mathrm{C}\right)$ with $12 \mathrm{hrs}$ fluorescent light (approx. 2065 lumens) per 24-hr period. The soil surface was examined for teliospore germination using an Olympus SZX12 stereomicroscope with a magnification of $900 \times$ and the ocular fitted with an optical grid with divisions covering $1.2 \mathrm{~mm}^{2}$. For each soil type, the number of germinated and un-germinated teliospores was counted in five optical grids to determine the percentage of germinated teliospores. Data were collected at $0,7,10,12,15,22,25,34,42$ and 48 days. The study was repeated three times.

\subsection{Effects of Soil Moisture and Temperature on Teliospore Germination}

Five-year mean weekly minimum/maximum air temperature data for the period of time between wheat planting and the infection window at anthesis were provided by the Food and Environment Research, York, UK, for Boxworth, United Kingdom (UK): October-May (Table 2); Oslo, Norway (NOR): September-May (Table 3); Amendola, Italy (IT): October-May (Table 4) and Szolnuk, Hungary 
Table 2. Mean Min/Max weekly temperatures for Boxworth, UK from wheat planting date through anthesis.

\begin{tabular}{|c|c|c|c|c|c|c|c|}
\hline Week & Min C & $\operatorname{Max} C$ & Date & Week & Min C & $\operatorname{Max} C$ & Date \\
\hline 1 & 8.2 & 12.4 & & 16 & 0.8 & 4.2 & $1-\mathrm{Feb}$ \\
\hline 2 & 6.3 & 10.9 & & 17 & 1.3 & 4.4 & \\
\hline 3 & 5.2 & 9.7 & $1-\mathrm{Nov}$ & 18 & -0.4 & 2.4 & \\
\hline 4 & 4.7 & 8.2 & & 19 & 0.0 & 2.7 & \\
\hline 5 & 4.4 & 7.2 & & 20 & 0.8 & 4.6 & 1-Mar \\
\hline 6 & 2.7 & 5.4 & & 21 & 1.9 & 6.8 & \\
\hline 7 & 2.3 & 5.7 & 1-Dec & 22 & 2.0 & 6.7 & \\
\hline 8 & 2.9 & 5.6 & & 23 & 2.4 & 7.4 & \\
\hline 9 & 2.1 & 5.0 & & 24 & 3.1 & 8.5 & 1-Apr \\
\hline 10 & 3.2 & 6.0 & & 25 & 3.1 & 8.5 & \\
\hline 11 & 3.3 & 5.7 & & 26 & 3.6 & 10.6 & \\
\hline 12 & 1.9 & 4.4 & 1-Jan & 27 & 5.6 & 12.5 & \\
\hline 13 & 0.6 & 3.8 & & 28 & 5.1 & 12.8 & \\
\hline 14 & 0.5 & 2.5 & & 29 & 7.1 & 14.7 & 1-May \\
\hline 15 & 0.7 & 3.3 & & 30 & 7.7 & 15.0 & \\
\hline
\end{tabular}

Table 3. Mean Min/Max weekly temperatures for Oslo, Norway from wheat planting date through anthesis.

\begin{tabular}{|c|c|c|c|c|c|c|c|}
\hline Week & Min C & $\operatorname{Max} C$ & Date & Week & Min C & $\operatorname{Max} C$ & Date \\
\hline 1 & 2.5 & 10.5 & & 18 & -13.4 & -4.1 & \\
\hline 2 & 3.2 & 11.5 & & 19 & -11.4 & -3.6 & \\
\hline 3 & 1.8 & 8.6 & $1-\mathrm{Oct}$ & 20 & -9.6 & -2.0 & 1-Feb \\
\hline 4 & 1.5 & 7.9 & & 21 & -11.3 & -1.7 & \\
\hline 5 & -1.1 & 4.6 & & 22 & -7.1 & 1.5 & \\
\hline 6 & -2.6 & 2.4 & & 23 & -5.0 & 2.7 & \\
\hline 7 & -4.9 & 0.0 & $1-\mathrm{Nov}$ & 24 & -6.4 & 2.9 & 1-Mar \\
\hline 8 & -3.8 & 1.0 & & 25 & -7.1 & 3.1 & \\
\hline 9 & -5.3 & -0.8 & & 26 & -4.3 & 4.2 & \\
\hline 10 & -5.5 & -1.0 & & 27 & -2.3 & 6.1 & \\
\hline 11 & -5.5 & 0.1 & 1-Dec & 28 & -2.1 & 7.3 & 1-Apr \\
\hline 12 & -9.6 & -3.3 & & 29 & -1.6 & 7.7 & \\
\hline 13 & -10.8 & -4.4 & & 30 & 0.6 & 9.5 & \\
\hline 14 & -11.7 & -6.1 & & 31 & 1.8 & 11.8 & \\
\hline 15 & -9.1 & -3.4 & & 32 & 2.4 & 12.4 & \\
\hline 16 & -5.1 & 0.2 & & 33 & 3.4 & 13.2 & 1-May \\
\hline 17 & -9.5 & -3.4 & & & & & \\
\hline
\end{tabular}


Table 4. Mean Min/Max weekly temperatures for Amendola, Italy from wheat planting date through anthesis.

\begin{tabular}{|c|c|c|c|c|c|c|c|}
\hline Week & Min C & Max C & Date & Week & Min C & Max C & Date \\
\hline 1 & 13.2 & 24.4 & $1-\mathrm{Oct}$ & 16 & 3.5 & 11.1 & \\
\hline 2 & 13.3 & 23.1 & & 17 & 4.3 & 12.6 & \\
\hline 3 & 11.2 & 22.2 & & 18 & 3.3 & 11.9 & 1-Feb \\
\hline 4 & 9.7 & 20.4 & & 19 & 4.3 & 11.4 & \\
\hline 5 & 8.6 & 18.8 & $1-\mathrm{Nov}$ & 20 & 2.8 & 12.0 & \\
\hline 6 & 9.1 & 18.3 & & 21 & 3.7 & 14.0 & \\
\hline 7 & 9.1 & 17.9 & & 22 & 4.6 & 14.9 & 1-Mar \\
\hline 8 & 5.4 & 13.7 & & 23 & 3.1 & 14.4 & \\
\hline 9 & 5.9 & 13.2 & 1-Dec & 24 & 4.6 & 14.5 & \\
\hline 10 & 5.4 & 12.6 & & 25 & 5.3 & 16.0 & \\
\hline 11 & 4.7 & 12.5 & & 26 & 4.4 & 14.8 & 1-Apr \\
\hline 12 & 5.9 & 12.8 & & 27 & 5.3 & 17.1 & \\
\hline 13 & 5.6 & 13.3 & & 28 & 6.3 & 17.4 & \\
\hline 14 & 4.7 & 11.5 & 1-Jan & 29 & 5.4 & 16.7 & \\
\hline 15 & 5.8 & 12.6 & & 30 & 7.6 & 19.2 & \\
\hline
\end{tabular}

(HUN): Sept.-April (Table 5). Similar data were obtained from the University of Arizona Meteorological Network (Tucson, AZ) weather station at the Regional Research Center, Cd. Obregon, Mexico (MX): November-March (Table 6); a location where Karnal bunt occurs.

These temperature profiles were entered weekly into five programmable environmental growth chambers set to ramp diurnally between the minimum and maximum daily temperatures. The duration of the temperature profiles varied based on the length of the wheat growing season of the country from which the temperature data were collected (e.g. 18 and 33 weeks for Mexico and Norway, respectively) and were obtained from the published Major World Crop Areas and Climate Profiles: Agriculture Handbook \#664 [19]. Growth chamber lighting was on a diurnal light cycle with the mean weekly temperature minimum occurring during the median of the 12-hr period of darkness. Fluorescent light (approx. 2065 lumens) was provided for the remaining $12 \mathrm{hrs}$. The minimum temperature capability of the growth chambers used in the simulation of the Norwegian and Hungarian temperature profiles was $-2^{\circ} \mathrm{C}$, therefore when desired profile temperatures were less than $-2^{\circ} \mathrm{C}$, the actual experimental temperature was $-2^{\circ} \mathrm{C}$.

The soil type used was the previously described clay loam from a wheat field in Arizona. Soil was autoclaved twice for $30 \mathrm{~min}$ then dried in an oven at $105^{\circ} \mathrm{C}$. Three SM conditions were tested for each growth chamber profile, $40.5 \%$ WHC 
Table 5. Mean Min/Max weekly temperatures for Szolnuk, Hungary from wheat planting date through anthesis.

\begin{tabular}{|c|c|c|c|c|c|c|c|}
\hline Week & Min C & $\operatorname{Max} C$ & Date & Week & Min C & $\operatorname{Max} C$ & Date \\
\hline 1 & 12.0 & 23.2 & & 16 & -4.6 & 1.1 & \\
\hline 2 & 10.0 & 19.2 & & 17 & -4.0 & 1.8 & 1-Jan \\
\hline 3 & 9.7 & 20.0 & & 18 & -1.7 & 4.1 & \\
\hline 4 & 8.3 & 18.7 & $1-\mathrm{Oct}$ & 19 & -4.6 & 1.1 & \\
\hline 5 & 8.0 & 19.6 & & 20 & -2.6 & 2.5 & \\
\hline 6 & 5.8 & 16.5 & & 21 & -4.4 & 2.2 & 1-Feb \\
\hline 7 & 3.3 & 14.1 & & 22 & -4.2 & 3.6 & \\
\hline 8 & 3.0 & 12.2 & $1-\mathrm{Nov}$ & 23 & -3.2 & 4.7 & \\
\hline 9 & 1.5 & 11.0 & & 24 & -0.3 & 7.0 & \\
\hline 10 & 3.7 & 11.3 & & 25 & 0.1 & 10.8 & 1-Mar \\
\hline 11 & -0.1 & 6.4 & & 26 & 0.2 & 10.5 & \\
\hline 12 & -0.7 & 4.4 & 1-Dec & 27 & -0.5 & 9.6 & \\
\hline 13 & -0.6 & 3.4 & & 28 & 0.3 & 9.0 & \\
\hline 14 & -2.5 & 2.2 & & 29 & -0.4 & 10.5 & 1-Apr \\
\hline 15 & -3.0 & 2.3 & & 30 & 3.1 & 14.7 & \\
\hline
\end{tabular}

Table 6. Mean Min/Max weekly temperatures for Cd.Obregon, Mexico from wheat planting date through anthesis.

\begin{tabular}{|c|c|c|c|c|c|c|c|}
\hline Week & Min C & $\operatorname{Max} C$ & Date & Week & Min C & $\operatorname{Max} C$ & Date \\
\hline 1 & 12.5 & 28.7 & $1-\mathrm{Nov}$ & 10 & 10.7 & 25.2 & 1-Jan \\
\hline 2 & 9.4 & 26.2 & & 11 & 8.9 & 23.6 & \\
\hline 3 & 12.5 & 26.6 & & 12 & 9.8 & 24.5 & \\
\hline 4 & 12.0 & 25.5 & & 13 & 9.0 & 24.4 & \\
\hline 5 & 10.8 & 23.1 & 1-Dec & 14 & 9.7 & 24.8 & 1-Feb \\
\hline 6 & 10.8 & 25.1 & & 15 & 8.9 & 26.0 & \\
\hline 7 & 11.1 & 25.2 & & 16 & 10.7 & 27.4 & \\
\hline 8 & 10.5 & 22.6 & & 17 & 10.3 & 27.9 & \\
\hline 9 & 9.8 & 23.4 & & & & & \\
\hline
\end{tabular}

$(20 \% \mathrm{w} / \mathrm{w})$ and $16.2 \% \mathrm{WHC}(8 \% \mathrm{w} / \mathrm{w})$, held constant in sealed plastic boxes throughout the experiment, and $40.5 \%$ WHC in uncovered boxes subjected to drying during the course of the week, then returned to $40.5 \%$ WHC the beginning of the following week, a process repeated for the duration of the experiment. Weight of the soil in the boxes was checked every seven days and water slowly added to maintain the appropriate moisture level as needed. 
For each growth chamber temperature profile, six plastic boxes $(28 \times 16 \times 6$ $\mathrm{cm}$ ) were filled with $240 \mathrm{~g}$ of soil that had been broken up in a blender to reduce large clumps of aggregated soil. Miracloth ${ }^{\circledR}$ (Calbiochem, La Jolla, CA) was glued to the bottom of numerous small plastic rings, each6 $\mathrm{mm}$ deep, manufactured from $2 \mathrm{~cm}$ ID PVC electrical conduit (CANTEX, Inc., Fort Worth, TX). Rings were filled to the top with $2.5 \mathrm{~g}$ of soil and pressed into the soil in the box with the top of the ring level with the surrounding soil surface (Figure 4). Total soil weight in each box was $260 \mathrm{~g}$.

For each growth chamber profile, $65.0 \mathrm{~g}$ of water were added to each of four boxes to establish a SM level of $40.5 \%$ WHC. Twenty-seven grams of water were added to the remaining two boxes to establish $16.2 \%$ WHC. Lids were applied to the boxes and the moisture allowed equilibrating throughout the soil for several days.

Each treatment was inoculated with $T$. indica teliospores in the spore settling tower with three $30 \mathrm{mg}$ inoculations for a total of $90 \mathrm{mg}$ per treatment.

At the time of inoculation, three sample rings were randomly removed from each treatment to establish the initial teliospore extraction efficacy and the baseline germination potential at the onset of the study. Box weights were adjusted to compensate for the removal of the sample rings and soil. Subsequently, three replicate samples were randomly removed at $3,4,9,1622,27$, and 31 weeks, depending on the length of the environmental growth chamber profile.

For each sampling time, the soil in each sample ring was transferred to a $50-\mathrm{ml}$ conical centrifuge tube with cap, suspended using a vortex in $35 \mathrm{ml}$ of Tween-20 water, then placed horizontally on an orbital shaker $(190 \mathrm{rpm})$ for 15 min. Using a modified version of Peterson et al. [13], the suspension was poured through a $53-\mu \mathrm{m}-\mathrm{mesh}$ screen, the tube and screen were rinsed with up to $500 \mathrm{ml}$ of water from a spray nozzle, all collected in a $600-\mathrm{ml}$ beaker. The filtrate then was poured through a $20-\mu \mathrm{m}$ mesh screen, the contents on the screen rinsed with approx. $100 \mathrm{ml}$ of water and the debris on the screen was rinsed back into the original $50-\mathrm{ml}$ centrifuge tube. The suspension was incubated at $17^{\circ} \mathrm{C}$ for $72 \mathrm{hrs;}$ the debris was pelleted by centrifugation at $600 \times \mathrm{G}$ for $5 \mathrm{~min}$, the supernatant

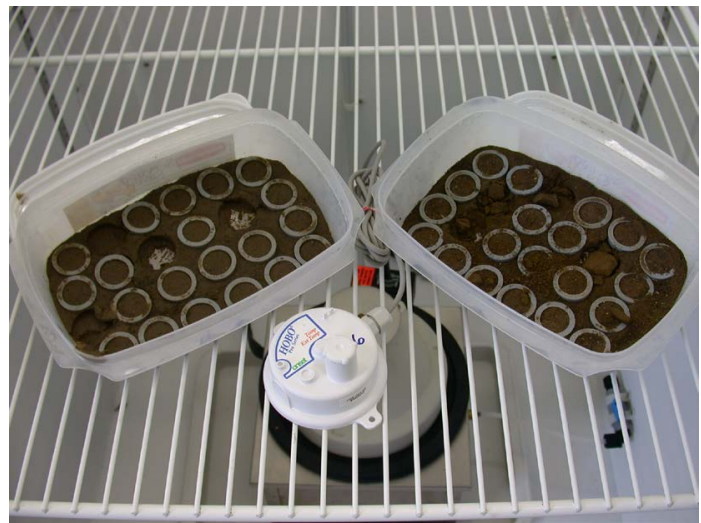

Figure 4. Soil boxes containing sample rings. 
was poured off, leaving the pellet lodged in the bottom. The tube was then inverted onto a paper towel to drain for $10 \mathrm{~min}$.

The pellet was suspended by vortex in $0.1 \%$ water agar, and $100 \mu \mathrm{l}$ of the suspension transferred to a $15-\mathrm{ml}$ conical centrifuge tube. Ten milliliters of acidic electrolytic water [11] was added to the $15-\mathrm{ml}$ centrifuge tube and placed on a rocker for $30 \mathrm{~min}$. It was then centrifuge-washed twice for 5 minutes at $600 \times \mathrm{G}$, suspended in $300 \mu \mathrm{l}$ of sterile water, and seeded onto $2 \%$ water agar in $10-\mu \mathrm{l}$ aliquots by the method of Inman et al. [20]. The number of germinated teliospores was assessed by light microscopy after 14 days incubation at $17^{\circ} \mathrm{C}$.

Concurrently, $50 \mu \mathrm{l}$ of the $0.1 \%$ water agar suspension in was pipetted into a $1.5 \mathrm{ml}$ microfuge tube. Shear's mounting medium $(50 \mu \mathrm{l})$ was added to the tube and suspended by vortexing. A sample $(40 \mu \mathrm{l})$ was transferred to a microscope slide, and a $22^{2} \mathrm{~mm}$ cover slip added. The total number of teliospores on the slide was determined by direct microscopic examination at $200 \times$.

Data obtained were the total number of teliospores recovered from each sample and the percent of that population which germinated. These data were used to estimate the numbers of un-germinated teliospores remaining on the soil surface over the advancing periods of time teliospores were exposed to the three moisture and five temperature profiles. The experiment was replicated three times. Analysis of variance was used to compare both the percentage of teliospores recovered and the germination percentages of those teliospores for all SM treatments within each temperature simulation and among all of the profiles.

Proportion of teliospores germinating on soils held at 16.2\% WHC, 40.5\% WHC, and fluctuating WHC for HUN, IT, UK, MX and NOR profiles was analyzed with the GLIMMIX procedure of SAS. The average proportion germination of three samples in each replication on soils from each country was analyzed. Replications were then re-structured as replications within countries, i.e., each country and replication within country combination was considered a single replication. The model analyzed was proportion teliospore germination equaled SM content, as a discrete variable, and within SM contents, days after seeding soil rings with teliospores as a continuous variable. These data were considered fixed variables with normally distributed errors and a logit link function. Replication was considered a random variable. Least squares means for each of the moisture contents were generated and statistically compared. Among the different moisture content treatments, estimate statements were written to compare linear slopes of changes in proportion teliospore germination with time (as days after applying teliospores to the soil surface).

\subsection{Observed Teliospore Germination under MX and HUN Conditions}

Forty grams of autoclaved and oven dried clay loam from an Arizona wheat field was transferred to $27100-\mathrm{ml}$ round plastic sealable containers(Lock \& Lock, Anaheim, CA), three per treatment, and a $6 \mathrm{~cm}$ dia. $\times 0.5 \mathrm{~cm}$ high plastic ring 
was set into the soil of each (Figure 3). The containers and contents were weighed, and then $13-16 \mathrm{ml}$ of distilled water were slowly atomized over the surface of the soil. Containers were sealed overnight so the moisture would come to equilibrium throughout the soil, the lids removed and the water allowed to evaporate for one to two days. Afterwards, the containers were weighed. For 18 of the containers, distilled water was added until the SM content reached 40.5\% WHC. For the remaining nine containers, distilled water was added until the moisture content reached $16.2 \%$ WHC. Lids were replaced and the samples held for 2 days in an incubator at $25^{\circ} \mathrm{C}$.

There were three temperature treatments used: the mean weekly minimum/ maximum temperature profile for MX and HUN and a treatment where the temperature remained between $18^{\circ} \mathrm{C}$ and $22^{\circ} \mathrm{C}$. Growth chamber lighting was on a diurnal light cycle with the mean weekly temperature minimum occurring during the median of the 12-hr period of darkness. Fluorescent light (approx. 2065 lumens) was provided during the remaining $12 \mathrm{hrs}$. The minimum temperature capability of the growth chambers used in simulation of the Hungarian temperature profile was $-2^{\circ} \mathrm{C}$, therefore when the desired temperatures were less than $-2^{\circ} \mathrm{C}$, the actual experimental temperature was $-2^{\circ} \mathrm{C}$.

In this experiment, two open $40.5 \%$ WHC containers and one $16.2 \%$ WHC container were loaded into the settling tower and inoculated with three $20 \mathrm{mg}$ clouds of teliospores for a total of $60 \mathrm{mg}$ per inoculation.

After inoculation, lids were replaced on half of the samples with the $40.5 \%$ WHC and all of those with $16.2 \%$. The remaining $40.5 \%$ WHC samples were left open (without lids). Three replications for each of the SM treatments were loaded into each programmed growth chamber. Samples with the lids off were allowed to dry down over a week, and then water content returned to $40.5 \%$ WHC. The soil surface within the plastic ring was examined for teliospore germination as previously described. Germination data for all treatments were collected 24 times over 206 days. The study was replicated three times.

\subsection{Statistical Analysis}

Analysis of variance was performed to test the variation between replications for each soil type [21]. Bonferroni LSD method was used when comparing the effects of soil type on teliospore germination.

Analysis of variance was used to compare percentages of teliospores recovered from soil samples over time for each simulated treatment as well as the percentage of germinating teliospores [21]. Tukey's ad hoc analysis was performed to compare the number of germinating teliospores recovered over time between temperature profiles. Transformed least squares mean was used to detect differences between teliospores germination in each simulated temperature profile [22].

Values were averaged over the various subsamples within a replicate. The resultant time/soil type averages for each of the three replicates were analyzed by 
ANOVA separating the variability due to replications. Bonferroni LSDs were used to determine differences within each of these factors and interactions [22].

\section{Results and Discussion}

\subsection{Inoculum Production}

One hundred percent of boot injected wheat variety "Cavalier" produced bunted kernels during all crop cycles.

\subsection{Teliospore Germination on the Surface in Different Soils}

Observed germination on the soil surface (Figure 5) was significantly lower for the sandy loam soil when compared to that on clay loam but it was not significantly different when compared to loam and sandy clay loam.

For all soil types, the germination rate on the soil surface over the course of the study was lowest at 7 and 10 days when compared to the maximum at 15 days but not significantly different from the observations made after 15 days. The lower germination at 7 to 10 days would be expected since this would also be the delay observed when plating teliospores on media for germination (Table 7).

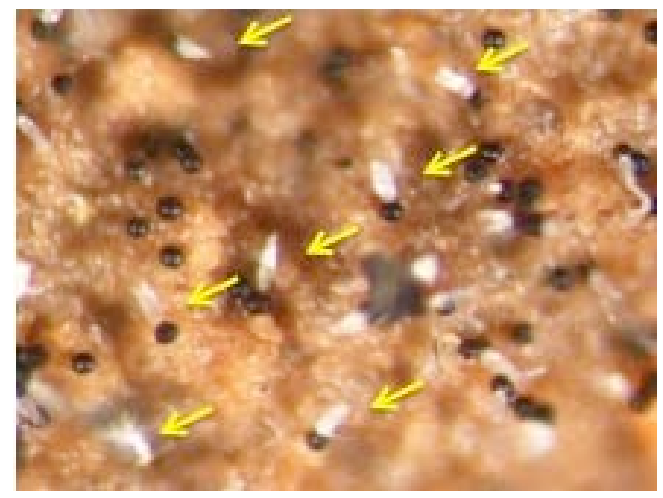

Figure 5. Teliospores germinating on the soil surface $(200 \times)$.

Table 7. Effect $=$ Germination over time.

\begin{tabular}{cccc}
\hline Days & Estimate & Standard Error & Letter Group $^{1}$ \\
\hline 7 & 0.7280 & 2.1403 & $\mathrm{C}$ \\
10 & 5.8913 & 2.1403 & $\mathrm{BC}$ \\
12 & 9.8169 & 2.1403 & $\mathrm{AB}$ \\
15 & 14.2607 & 2.1403 & $\mathrm{~A}$ \\
22 & 13.2784 & 2.1403 & $\mathrm{AB}$ \\
26 & 9.7829 & 2.1403 & $\mathrm{AB}$ \\
34 & 9.2617 & 2.4998 & $\mathrm{ABC}$ \\
42 & 6.6750 & 2.4998 & $\mathrm{ABC}$ \\
48 & 5.3764 & 2.4998 & $\mathrm{ABC}$ \\
\hline
\end{tabular}

${ }^{1}$ Days with no letter in common are significantly $[p<0.05]$ different by the Bonferroni LSD method. 
There was no significant difference on observed teliospore germination on different soils with the exception of sandy loam from Kansas that did differ from clay loam and silt loam but not the others (Table 8). Although soil type may play a role in the long-term survival of teliospore within the soil [23], it appears to have a limited effect on the viability of teliospores present on the soil surface during the first season.

\subsection{Effects of Soil Moisture and Temperature on Teliospore Germination}

The mean number of teliospores per soil ring, based on teliospore counts made on water agar dishes from the spore-settling tower, was estimated as 9,870 (SD $1,518.7)$ teliospores per $3.14 \mathrm{~cm}^{2}\left(3,143\right.$ per $\left.\mathrm{cm}^{2}\right)$. The mean extraction efficiency calculated on the samples tested at the beginning of the study (zero days) was $53.3 \%$.

Within each of the simulated temperature profiles, analysis of variance among the three replicated experiments for the different SM treatments indicated no significant differences $(p \leq 0.05)$ for the percentage of teliospores recovered from the soil samples over time for HUN $(p=0.9739)$, IT $(p=0.9842)$, UK $(p=$ $0.9248), \operatorname{MX}(p=0.8865)$ and NOR $(p=0.8858)$. Likewise, for the population of teliospores recovered from each of the SM treatment samples over time, no differences were detected in the percentage of those teliospores that germinated for HUN $(p=0.9739)$, IT $(p=0.0844), \mathrm{UK}(p=0.5217), \mathrm{MX}(p=0.8816)$ and NOR $(p=0.1318)[21]$.

When comparing SM treatments between the different temperature profiles, analysis of variance $(p \leq 0.05)$ indicated no differences among the percentage of teliospores recovered from the samples subjected to fluctuating SM conditions $(p=0.3971)$ [21]. Significant differences were observed in the number of teliospores recovered over time for $40.5 \%$ WHC $(p=0.0003)$ and $16.2 \%$ WHC $(p=$ 0.032). Tukey's ad hoc analysis for $40.5 \%$ WHC showed differences occurring between HUN-MX $(p<0.05)$ and HUN-NOR $(p<0.01)$ and between IT-NOR $(p<0.05)$ and UK-NOR $(p<0.05)$.

For each SM treatment, an analysis of variance between the temperature profiles for the percentage of recovered teliospores that germinated throughout the

Table 8. Effect = soil type

\begin{tabular}{cccc}
\hline Soil Type & Estimate & Standard Error & Letter Group* \\
\hline Clay Loam & 9.5196 & 1.8872 & $\mathrm{~A}$ \\
Loam & 8.4201 & 1.8872 & $\mathrm{AB}$ \\
Sandy Clay Loam & 7.6603 & 1.8872 & $\mathrm{AB}$ \\
Sandy Loam & 3.2854 & 1.8872 & $\mathrm{~B}$ \\
Silt Loam & 12.8208 & 1.8872 & $\mathrm{~A}$ \\
\hline
\end{tabular}

${ }^{\star}$ Soil types with no letter in common are significantly $[p<0.05]$ different by the Bonferroni LSD method. 
study indicated no differences between those samples subjected to fluctuating WHC conditions $(p=0.3511)$ or samples collected from the $40.5 \%$ WHC soil moisture treatments $(p=0.0852)$. Significant differences in germination of recovered teliospores over time were detected for teliospores subjected to $16.2 \%$ WHC ( $p=0.0109)$, with Tukey's ad hoc analysis identifying the difference occurring between the HUN-UK temperature profiles $(p \leq 0.05)$.

Back-transformed least squares means, from logit values, for each of the SM contents, at the average time after seeding soil rings, i.e., 109.7 days, the germination percentages for those teliospores recovered from the samples, were $31.3 \%, 24.4 \%$, and $30.4 \%$ for $40.5 \%$ WHC, $16.2 \%$ WHC, and fluctuating WHC content, respectively. Based on logit values, germination at $16.2 \% \mathrm{WHC}$ was significantly $(p \leq 0.05)$ greater than germination at $40.5 \%$ WHC, which, in turn, was significantly less than germination at fluctuating moisture content. All three estimates were significantly greater than zero. None of the slope estimates at the different moisture contents were significantly greater than zero, and there were no significant differences among slopes.

In the absence of teliospore dormancy, one would expect that if teliospores on the soil were exposed to early conducive conditions they would germinate and not be present later in the simulated season when wheat is susceptible to infection. This was not observed in the simulations of mean $\min / \max$ temperature conditions for four European wheat-growing regions during their wheat season. When looking at the average percent of teliospores recovered over time, there was a trend of gradual population decline for all simulations exception for NOR, however the trend was not statistically significant. During the NOR simulation, much of the time the min/max temperatures were close to or below freezing, making it unlikely the germination would occur.

There was no statistically significant decline in viability of teliospores extracted from the soil surface over time. In this study, the direct observation on soil and quantification of germinating teliospores was not determined, but rather the viability of the teliospore recovered from the soil. It should be noted that the process of surface sterilizing the teliospores with acidic electrolytic water [11] prior to seeding water agar dishes has been shown to increase teliospore germination. This limits our conclusion to the observation that over the course of the experimental temperature simulations a portion of the teliospores are capable of germination during the time period of the study.

\subsection{Observed Teliospore Germination on Soil under MX and HUN Conditions}

There were no significant differences among replication detected for the direct observation of teliospores germinating on the soil surface when subjected to the MX, HUN and $18-22^{\circ} \mathrm{C}$ temperature profiles, so data from each treatment were pooled. Low levels of teliospore germination were observed throughout MX 114-day simulation of temperature conditions from the regional planting date to 
anthesis. The greatest percentage of teliospore germination was observed in the 16.2\% WHC and 40.5\% WHC treatments (18.21 and 5.8\%, respectively) and occurred during the time period when wheat plants would be susceptible to disease. In contrast, during the HUN 225-day simulation, the largest percentage of teliospore germination on the soil was observed during the simulated period of time that corresponded to the first 30 days after planting for both the $40.5 \%$ and fluctuating $40.5 \%$ treatments, and only trace level of germination occurred when wheat would expect to be heading. When soil temperature was held at $18-22^{\circ} \mathrm{C}$ for 114-days, teliospores subjected to $40.5 \%$ WHC germinated at a much greater rate during the first 30 days of the study (11.22\%). In contrast teliospores subjected to $16.2 \%$ WHC had the highest level of soil surface germination during the last 30 days of the experiment (Table 9).

In the HUN simulation, the greatest percentage of teliospores germinated within the first 30 days [after simulated planting date], most predominately those subjected to the $40.5 \%$ WHC and those that began each week at $40.5 \%$ WHC and were allowed to dry down until adjusted back to $40.5 \%$ the following week. Between thatperiod; until the last 30 days; only trace germination was observed. During the last 30 days (simulated period of wheat heading), the predominate period of germination occurred with teliospores subjected to $16.2 \%$ WHC (Figure 6).

Those teliospores subjected to the simulated $\mathrm{min} / \mathrm{max}$ temperature simulations based on temperature data from Ciudad Obregon, MX, where Karnal bunt occurs, behaved differently. Low levels of germination were observed primarily on teliospores subjected to $40.5 \%$ WHC and less in the other two moisture treatments for the first 80 days. After 84 days, corresponding to the simulated period of wheat heading in $\mathrm{Cd}$. Obregon, germination of the teliospores subjected to $16.2 \%$ WHC abruptly rose to over $25 \%$ for the remainder of the study. The teliospores in the $40.5 \%$ WHC treatment also increased significantly in relation to its percent germination earlier in the time line (Figure 7).

In the final treatment, temperature in the growth chamber was set at $18^{\circ} \mathrm{C}$ and

Table 9. Average percentage of germinating teliospores observed during different time periods over the course of the study.

\begin{tabular}{|c|c|c|c|c|c|c|c|c|c|}
\hline Days & $\mathrm{MX}-40.5 \%$ & $\begin{array}{l}\text { HUN- } \\
40.5 \%\end{array}$ & $\begin{array}{c}18 \mathrm{C}- \\
40.5 \%\end{array}$ & $\begin{array}{c}\text { MX- } \\
16.2 \%\end{array}$ & $\begin{array}{l}\text { HUN- } \\
16.2 \%\end{array}$ & $\begin{array}{c}18^{\circ} \mathrm{C} \\
\mathrm{C}-16.2 \%\end{array}$ & MX-Fluc & HUN-Fluc & 18C-Fluc \\
\hline $1-30$ & 2.149 & 10.160 & 11.122 & 0.068 & 0.661 & 0.382 & 0.107 & 8.618 & 0.588 \\
\hline $31-60$ & 1.545 & 0.335 & 0.666 & 0.118 & 1.030 & 0.000 & 0.462 & 2.449 & 2.396 \\
\hline $61-90$ & 3.748 & 0.320 & 1.080 & 0.000 & 0.326 & 0.000 & 1.451 & 0.262 & 0.000 \\
\hline $91-120$ & 5.811 & 0.000 & 2.718 & 18.215 & 0.000 & 12.779 & 2.994 & 0.196 & 6.818 \\
\hline $121-150$ & . & 0.121 & . & . & 0.000 & . & . & 0.164 & . \\
\hline $151-180$ & . & 0.000 & . & . & 0.121 & . & . & 0.000 & . \\
\hline $181-210$ & . & 0.000 & . & . & 2.983 & . & . & 0.000 & . \\
\hline $211-225$ & . & 0.126 & . & . & 0.000 & & & 0.000 & . \\
\hline
\end{tabular}




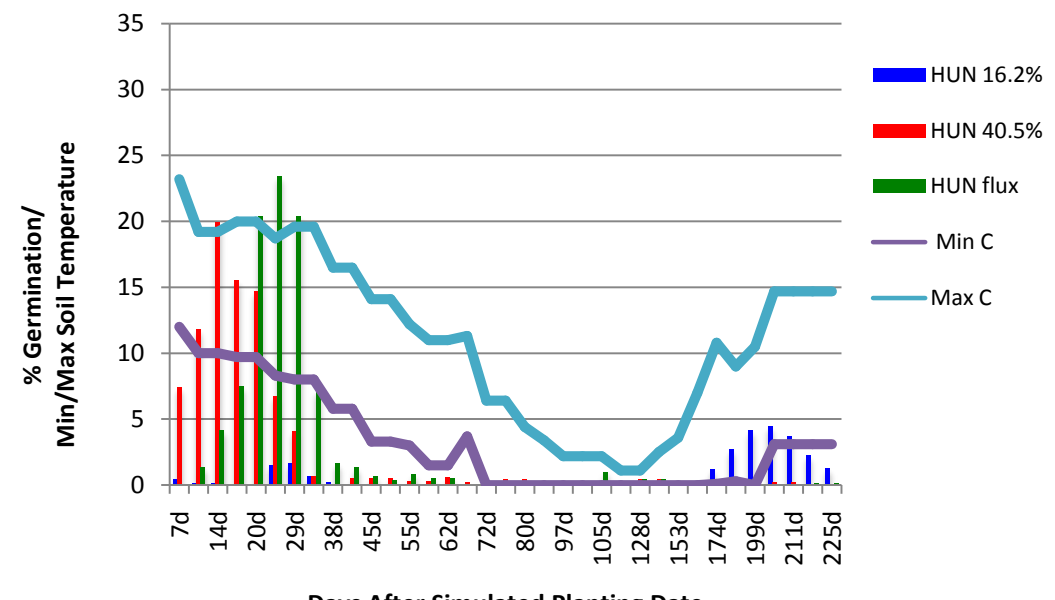

Figure 6. Observed $T$. indica teliospore germination on the soil surface under simulated HUN temperature conditions and three moisture treatments.

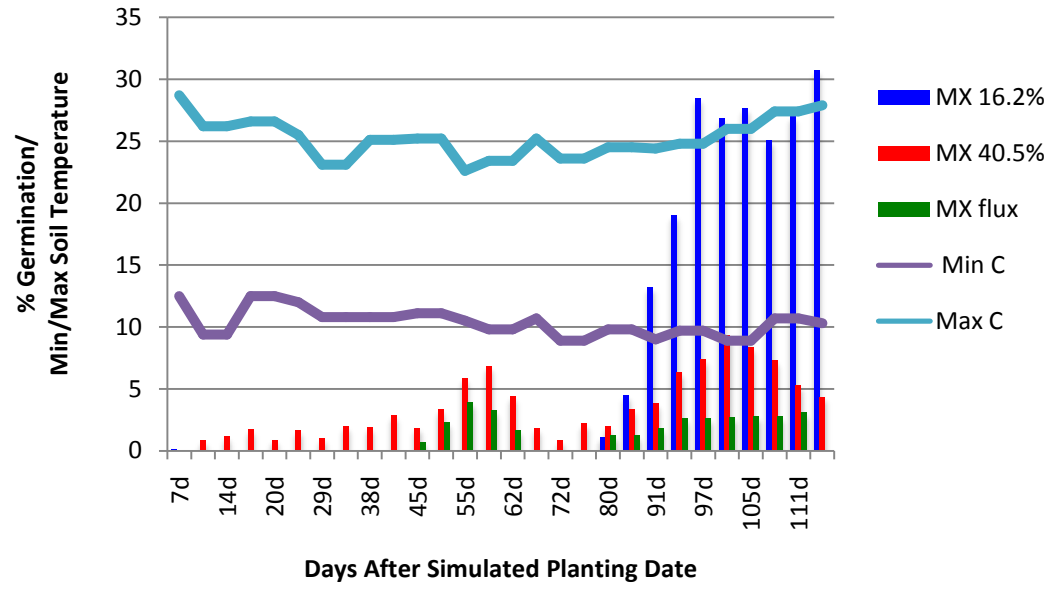

Figure 7. Observed T. indica teliospore germination on the soil surface.

fluctuated between $18^{\circ} \mathrm{C}$ and $22^{\circ} \mathrm{C}$. In this case we observed that the highest observed germination of teliospores subjected to $40.5 \%$ WHC soil occurred in the first 30 days whereas the highest germination for the $16.2 \%$ WHC treatment occurred after 90 days with some notable increase in the germination of the $40.5 \%$ treatment (Figure 8). Because $18^{\circ} \mathrm{C}$ treatment is a relatively constant temperature, initial speculation as to why there is a substantial decrease in germination between roughly 30- and 90 days for MX and 30 to 190 days for HUN, cannot be attributed solely to temperature during that time period but may suggest an extended period of time required for teliospores to hydrate when surface SM is low.

With the exception of the first 30 days of the HUN profile, germination of teliospores subjected to fluctuating moisture levels is relatively low throughout all of the temperature treatments. Based on the previous experiment, it appears the fluctuation is not detrimental to the teliospores since it had no effect on the germination of the spores extracted from the treatment. In the HUN profile, the 


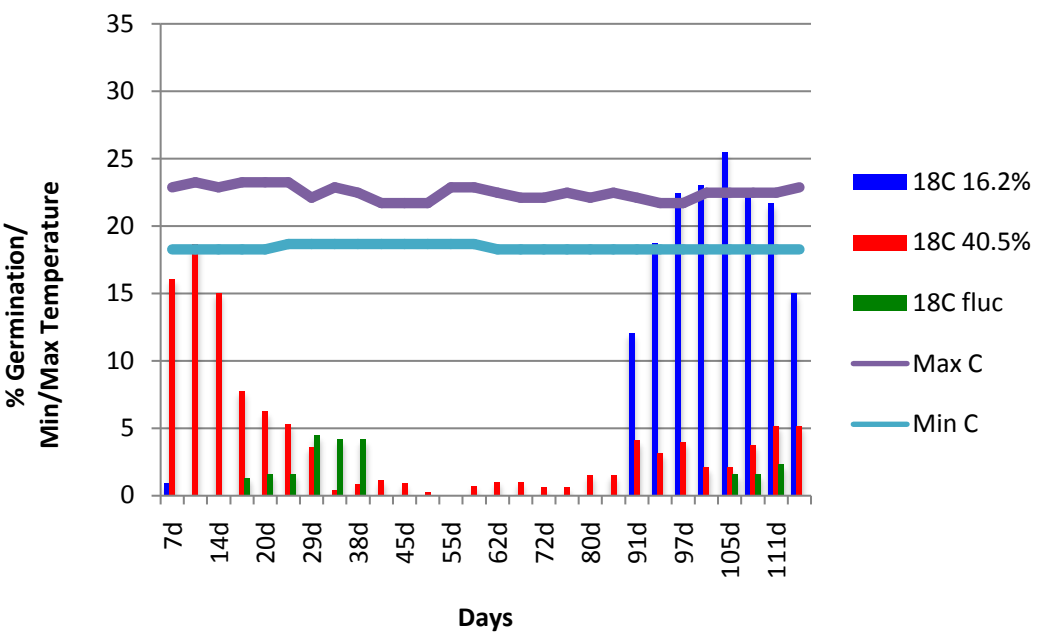

Figure 8. Observed $T$. indica teliospore germination on the soil surface over 16 weeks at $18-22^{\circ} \mathrm{C}$ and subjected to three moisture treatments.

lower minimum temperature during that time period may have slowed down SM evaporation, allowing the teliospores to hydrate while still within a favorable germination temperature range.

The goals of the three studies presented here were to first determine if soil type had an effect on the germination of teliospores on the soil surface; determine if the effect of SMca used viable population decline under several simulated European regional temperature simulations in contrast to a region where Karnal bunt occurs, and lastly, by direct observation, determine the timing of teliospore germination on the soil surface in simulated Hungarian and Mexican temperature regimes during their wheat growing seasons.

Results suggest that when early season surface soil conditions are dry, the majority of teliospores would remain in stasis until more favorable SM conditions occur. These kinds of conditions are common in the regions where the disease occurs. In those regions, [e.g., Sonora, Mexico; Arizona, U.S.A.; South Africa and Punjab, India] the soil surface dries quickly after irrigation is applied when no host canopy is present to slow down the evaporation rate. It may also be relevant that when a newly planted field is flood irrigated, solar radiation will rapidly heat the surface water to temperatures inhibitory to teliospore germination [23]. In Arizona, hourly soil temperatures were recorded for three days after flood irrigation was applied and soil temperature averaged $35.6^{\circ} \mathrm{C}(\mathrm{SD} 9.3)$ with a min/max of 22.7 to $63.6^{\circ} \mathrm{C}$, respectively (Peterson \& Kosta, unpublished data).

\section{Conclusion}

In summary, the data strongly suggest that in many dry-land (non-irrigated) wheat-growing regions that undergo a series of rain events in early season, the majority of viable teliospores on the soil surface will germinate outside the window of host infection. Likewise, intermittent rainfall that results in fluctuating surface SM may have a similar effect. In both scenarios however, a portion of 
these teliospores will remain viable up to the period when wheat is vulnerable to infection and if SM and sub-canopy environment are favorable for teliospore germination, some level of inoculum will should be expected. This however would not imply that infection would necessarily occur if favorable conditions for wheat infection; high humidity, cool temperatures and light rainfall, were not present in the upper canopy during the narrow window for host infection [1] [2] [24].

\section{Acknowledgements}

We thank USDA ARS FDWSRU Support Scientist Deborah Glenn-Parrish who coordinated much of the work on these projects as well as the support of Biological Technician, Kathy Fronda and former student, Christine Layton. Plant Pathologist Kathleen Kosta, California Dept. of Food and Agriculture, assisted in the inoculation and harvesting of infected seed from wheat plants in experimental plots in Maricopa, Arizona. We thank Morris Bonde and William Bruckart of FDWSRU for their reviews and comments.

Mention of trade names or commercial products in this publication is solely for the purpose of providing specific information and does not imply recommendation or endorsement by the U.S. Department of Agriculture. USDA is an equal opportunity provider and employer.

\section{References}

[1] Bonde, M.R., Peterson, G.L., Schaad, N.W. and Smilanick, J.L. (1997) Karnal bunt of Wheat. Plant Disease, 81, 1370-1377.

https://doi.org/10.1094/PDIS.1997.81.12.1370

[2] Sansford, C.E. (1998) An Assessment of the Significance of the Initial Detection of Tilletia indica Mitra in the USA in Early 1996 and the Potential Risk to the United Kingdom [and the European Union]. In: Malik, V.S. and Mathre, D.E., Eds., Bunts and Smuts of Wheat: An International Symposium, North American Plant Protection Organization, Ottawa, 273-302.

[3] Warham, E.J. (1986) Karnal Bunt Disease of Wheat: A literature Review. Tropical Pest Management, 32, 229-242. https://doi.org/10.1080/09670878609371068

[4] Torarbi, M., Mardoukhi, V. and Jalaiani, N. (1996) First Report on the Occurrence of Partial Bunt on Wheat in the Southern Parts of Iran. Seed and Plant, 12, 8-9.

[5] Duran, R. (1972) Further Aspects of Teliospore Germination in North American Smut Fungi II. Canadian Journal of Botany, 50, 2569-2573.

https://doi.org/10.1139/b72-329

[6] Da Luz, W.C., Mendes, M.A.S., Ferreira, M.A.S.V. and Urben, A.F. (1993) Tilletia indica on Wheat in the South of the State of Rio Grande do Sul, Brazil and Measures for Eradication. Fitopatologica Brasileira, 18, S329.

[7] Crous, P.W., Van Jaarsveld, A.B., Castlebury, L.A., Carris, L.M., Frederick, R.D. and Pretorius, Z.A. (2001) Karnal Bunt of Wheat Newly Reported from the African Continent. Plant Disease, 85, 561. https://doi.org/10.1094/PDIS.2001.85.5.561B

[8] Ykema, R.E., Floyd, J.P., Palm, M.E. and Peterson, G.L. (1996) First Report of Karnal Bunt of Wheat in the United States. Plant Disease, 80, 1207.

https://doi.org/10.1094/PD-80-1207B 
[9] Joshi, L.M., Singh, D.V., Srivastava, K.D. and Wilcoxson, R.D. (1983) Karnal Bunt: A Minor Disease That in Now a Threat to Wheat. The Botanical Review, 49, 309-330. https://doi.org/10.1007/BF02861085

[10] Babadoost, M., Mathre, D.E., Johnston, R.H. and Bonde, M.R. (2004) Survival of Teliospores of Tilletia indica in Soil. Plant Disease, 88, 56-62. https://doi.org/10.1094/PDIS.2004.88.1.56

[11] Bonde, M.R., Nester, S.E., Khayat, A., Smilanick, J.L., Frederick, R.D. and Schaad, N.W. (1999) Comparison of Effects of Acidic Electrolyzed Water and $\mathrm{NaOCl}$ on Tilletia indica Teliospore Germination. Plant Disease, 83, 627-632. https://doi.org/10.1094/PDIS.1999.83.7.627

[12] Bonde, M.R., Nester, S.E., Olsen, M. and Berner, D.K. (2004) Survival of Tilletia in dica Teliospores in Arizona Field Soils. Plant Disease, 88, 804-810. https://doi.org/10.1094/PDIS.2004.88.8.804

[13] Peterson, G.L., Leth, V., Thinggaard, K. and Sansford, C.E. (2006) Report on Teliospore Dormancy and Germination under a Range of Abiotic Conditions, Interpreting the Results in Relation to European Conditions and Predicting the Likely Timing of Teliospore Germination in Europe. EU 'Karnal Bunt Risks' Project, Deliverable Report 4.1. http://karnalpublic.pestrisk.net/deliverables

[14] Melching, J.S., Bromfield, K.R. and Kingsolver, C.H. (1983) The Plant Pathogen Containment Facility at Frederick, Maryland. Plant Disease, 67, 717-722. https://doi.org/10.1094/PD-67-717

[15] Sansford, C., Baker, R., Brennan, J., Ewert, F., Gioli, B., Inman, A., Kelly, P., Kinsella, A., Leth, V., Magnus, H., Migietta, F., Murray, G., Peterson, G., Pota-Puglia, A., Porter, J., Refoss, T., Riccioni, L., Thorne, F. and Valvassori, M. (2006) Report on the Risk of Entry, Establishment and Socio-Economic Loss for Tilletia indica in the European Union (DL6.1) and Determination and Report on the Most Appropriate Risk Management Scheme for Tilletia indica in the EU in Relation to the Assessed Level of Risk (DL6.5). EC Fifth Framework Project QLK5-1999-01554: Risks Associated with Tilletia indica, the Newly-Listed EU Quarantine Pathogen, the Cause of Karnal Bunt of Wheat, Deliverable Reports $6 \cdot 1$ and $6 \cdot 5$.

http://karnalpublic.pestrisk.net/deliverables

[16] Bonde, M.R., Peterson G.L., Fuentes-Davila, G., Aujla, S.S., Nanda, G.S. and Phillips, J.G. (1996) Comparison of the Virulence of Isolates of Tilletia indica: Causal Agent of Karnal Bunt of Wheat, from India, Pakistan, and Mexico. Plant Disease, 80, 1071-1074. https://doi.org/10.1094/PD-80-1071

[17] Harding, D.E. and Ross, D.J. (1964) Some Factors in Low-Temperature Storage Influencing the Mineralisable Nitrogen of Soils. Journal of the Science of Food and Agriculture, 15, 829-834. https://doi.org/10.1002/jsfa.2740151203

[18] Rattan G.S. and Aulja S.S. (1992) Ecology of Germination of the Teliospore of Karnal Bunt Pathogen (Neovossia indica). Indian Journal of Agricultural Sciences, 62 , 228-231.

[19] USDA (1994) Major World Crop Areas and Climatic Profiles, Agricultural Handbook, No. 664. World Agricultural Outlook Board, U.S. Department of Agriculture.

[20] Inman, A., Magnus, H.A., Riccioni, L., Hughes, K., Coates, M., Barnes, A., Barton, V., Sansford, C.E., Valvassori, M., Di Giambattista, G., Porta-Puglia, A., Razzaghian, J. and Peterson, G.L. (2008) Survival of Tilletia indica Teliospores under European Soil Conditions. Plant Pathology, 57, 290-300. https://doi.org/10.1111/j.1365-3059.2007.01766.x

[21] AnalystSoft Inc. (2013) StatPlus 5.4. AnalystSoft Inc., Alexandria, VA. 
[22] SAS Institute Inc. (2008) SAS/STAT 9.2 User's Guide. SAS Institute Inc., Cary, NC.

[23] Kumar, J., Saharan, M.S., Sharma, A.K. and Nagarajan, S. (2003) Effect of Temperature on Teliospore Germination in Tilletia indica under Simulated Conditions and Its Relevance in Pest Risk Analysis in Wheat. Indian-Phytopathology, 56, 14-21.

[24] Mavi, H.S., Jhorar, O.P., Sharma, I., Singh, G.,Mahi, G.S., Mathauda, S.S. and Aujla, S.S. (1992) Forecasting Karnal Bunt Disease of Wheat-A Meteorological Method. Cereal Research Communications, 20, 67-74. 